\title{
Pharmacodynamics and Pharmacokinetics of oral factor Xa inhibitors
}

\section{Pontus B Persson}

Institute of Vegetative Physiology, Berlin, Germany
Correspondence: Pontus B Persson Institut für Vegetative Physiologie, Charitéplatz I, 10117 Berlin, Germany Tel +4930450528 I62

Email pontus.persson@charite.de
This article was published in the following Dove Press journal:

Clinical Pharmacology:Advances and Applications

II May 2015

Number of times this article has been viewed

\section{Dear Editor}

Apixaban and rivaroxaban are oral factor Xa inhibitors. In a recent issue of Clinical Pharmacology: Advances and Applications, Frost et al compare apixaban (2.5 mg, twice daily) to rivaroxaban (10 $\mathrm{mg}$, once daily) with regard to their pharmacokinetics and pharmacodynamics. ${ }^{1}$ Both oral factor Xa inhibitors have similar half-lives. Moreover, as may seem intuitive, the twice daily regime of apixaban revealed a less pronounced peak-to-trough plasma concentration ratio than rivaroxaban which is given once daily. The latter finding lead the authors to suggest a more constant anticoagulant effect of twice-daily apixaban, when compared to the once daily dose of rivaroxaban.

Suggesting more constant anticoagulation by the twice-daily apixaban regimen is premature due to the author's disregard of a crucial pharmacokinetic feature: drug accumulation. Apixaban may have accumulated during the twice-daily regimen, as indicated by the increasing trough values (see values for $12 \mathrm{~h}$ and $24 \mathrm{~h}$ in Figure 2 of that study). That Figure claims to show data at steady state, however, trough values rise, indicating drug accumulation after a time period, when a steady state is usually reached ( 5 half-lives). Uncontrolled accumulation cannot be ruled out.

Thus, part of the smaller peak-to-trough plasma concentration ratio is accounted for by non-steady-state conditions of the apixaban setting, ie, the plasma concentration of apixaban does not reach baseline before the second dose is provided. The discussion confirms the notion of apixaban accumulation. The authors point out that apixaban's anti-factor-Xa-activity persisted well beyond the time point at which the next scheduled dose was to be administered, whereas rivaroxaban anti-factor-Xa-activity was near or below the lower limit of the detection assay. ${ }^{1}$ Remarkably, it is further stated that anti-Xa is a sensitive test to determine the pharmacodynamics (assumably, the authors mean pharmacokinetics) of apixaban. However, the trough values for the anti-Xa values do not mirror the steady increase shown in Figure 2. In contrast, the trough at 12 hours is lower than after 24 hours. How is this discrepancy explained?

Further complicating the interpretation of Frost et al's study is the absence of tests for statistical significant differences and inconsistent reporting of data (eg, half-lives are presented as means, whereas the time-to-maximum concentration are provided as median values). What is more, the regression line for apixaban's anti-factor-Xa-activity extends fourfold beyond the actual measurements (Figure 4 of that study), and close inspection of the Figure raises doubts, whether the relationship for apixaban actually 
is linear: The values above 90 (ng/mL) seem to taper off, suggesting the onset of saturation. Adding to the difficulty of interpreting the data, the method section states, that 21 samples are taken for Rivaroxaban on day 4, and 22 samples for apixaban. However, Figure 2 reveals only 20 values for Rivaroxaban, but 23 for apixaban.

Finally, the author's conclusions that the clinical impact of the differences on the relative efficacy and safety of apixaban and rivaroxaban remain to be determined, surprises. The author's discussion highlights phase II clinical trials showing that apixaban shows lower rates of venous thromboembolism in patients undergoing knee replacement when give twice daily instead of once daily. ${ }^{2}$ Conversely, in patients undergoing hip replacement, safety and efficacy of rivaroxaban was found to be similar when given once daily or twice daily. ${ }^{3}$

\section{Disclosure}

PBP consults Bayer Diagnostics with regard to renal safety of X-ray contrast media. The author has no other conflicts of interest in this correspondence.

\section{References}

1. Frost $\mathrm{C}$, Song $\mathrm{Y}$, Barrett $\mathrm{YC}$ et al. A randomized direct comparison of the pharmacokinetics and pharmacodynamics of apixaban and rivaroxaban. Clin Pharmacol. November 13, 2014;6:179-187. doi: 10.2147/CPAA. S61131.eCollection@2014:179-187.

2. Lassen MR, Davidson BL, Gallus A, Pineo G, Ansell J, Deitchman D. The efficacy and safety of apixaban, an oral, direct factor Xa inhibitor, as thromboprophylaxis in patients following total knee replacement. J Thromb Haemost. 2007 December;5(12):2368-2375.

3. Eriksson BI, Borris LC, Dahl OE et al. A once-daily, oral, direct Factor Xa inhibitor, rivaroxaban (BAY 59-7939), for thromboprophylaxis after total hip replacement. Circulation. November 28, 2006;114(22):2374-2381.

\section{Publish your work in this journal}

Clinical Pharmacology: Advances and Applications is an international, peer-reviewed, open access journal publishing original research, reports, reviews and commentaries on all areas of drug experience in humans. The manuscript management system is completely online and includes a very quick and fair peer-review system, which is all easy to use.
Visit http://www.dovepress.com/testimonials.php to read real quotes from published authors. 